解説

Explanation

\title{
Hybrid Propulsion is Part of the Future for RoPax Ferries* \\ - Environmental and Efficiency Needs are the Drivers
}

\author{
Harald Tillung** Piero Zoglia** Nico Höglund ${ }^{* *}$
}

\section{Introduction}

Green is undoubtedly the colour concept most dominating today's shipping industry, and nowhere is this more true than in the ferry sector. Environmental considerations are, along with the need to optimize operational efficiency, high on the agenda of ferry operators around the world.

Norway has taken a leading position in the change to renewable energy, and the 'MF Folgefonn' was the world's first plug-in hybrid ferry. Wärtsilä technology was used in this project and the vessel has been featured as a demonstration of the possibilities this technology creates. The Norwegian ferry fleet is now undergoing a major renewal, and during the next few years it is envisioned that more than 30 new ferries will be built with either fully electric or plug-in hybrid propulsion. This can be seen as the leading edge of a trend that is likely to become a global phenomenon.

Hybrid systems are being featured more and more on a variety of vessel types, but are particularly relevant to ferries since they are more likely to be operating within areas covered by strict environmental regulations. RoPax ferries may have different operating profiles than smaller RoRo ferries, but the challenges and opportunities concerning hybrid propulsion are very similar.
*Received June 06, 2017
**Wärtsilä

\section{Power system configurations}

A detailed understanding of the ship's operational profile is necessary in order to select the most appropriate power system configuration. This is especially important when using hybrid systems with energy storage, since the trade-off between lifetime, cost, and operational flexibility depends on a good understanding of the ship's operations.

Furthermore, the selection and integration of the energy storage devices is also of paramount importance. The overall efficiency of the power system and the availability of the total system are naturally dependent upon the energy storage selected. The role of the power electronics will also become more important in the future. This is a result of the increased degree of freedom the system enables, and because the energy sources need to be connected to the onboard power distribution network.

As new energy sources and propulsion developments evolve, the future demands and possibilities should be taken into serious consideration during the planning of newbuild ferries. By beginning the system evaluation process at the earliest possible stage of the project, the best solution utilizing all the potential presented by the new sources and developments can be found. At the same time, it will mean that the vessel is prepared for future developments within the various energy sources. Figure 1 below provides an overview of the possible energy sources that could become available in the near future, and illustrates the importance of planning not only newbuilds, but also conversions, at an early stage. 


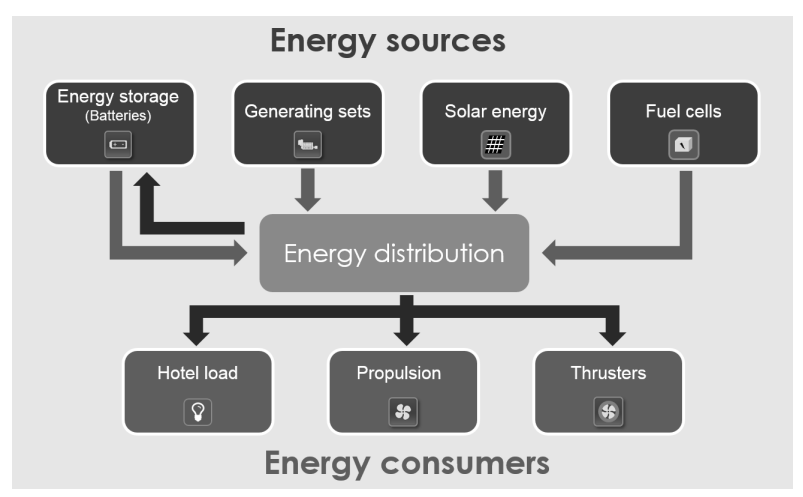

Fig.1 Energy sources and consumers

\section{Electrical system configuration}

Hybrid RoPax ferries will rely on having an adequate quay arrangement and shore power availability. The quay will be important for providing the needed power transfer facilities, while the challenge for the shore based power will be to assess how much is needed to be transferred to the vessel.

As a basic configuration, we see that in transit operations the most efficient operation is with direct mechanical propulsion. However, when manoeuvring or operating at low loads, it is normally more efficient to run with electric power. Thus, the right solution has to be one that takes these factors into consideration, since it is essential that the vessel is as efficient as possible at all times and in all operating conditions.

When designing the system, there are several factors that need to be taken into account. These include the envisioned operating profile, the route profile, the service speed, the maximum speed, the eventual availability of power from onshore facilities, and the onboard electrical consumers.

\section{Propulsion configuration}

As an example, we show here a solution using two 2 -speed reduction gearboxes, each equipped with one 12-cylinder Wärtsilä 31DF dual-fuel engine, and a Power Take-In (PTI) / Power Take-Off (PTO) unit. With a combination of the engine and PTI, the available propulsion power will be $10 \mathrm{MW}$ on each propeller. The design should be such that the vessel could run at normal service speeds with the main engines only. Other onboard consumers can, however, be supplied by running the PTI / PTO as a PTO generator. Additionally, the PTI / PTO will be the connection to the vessel's electrics including the batteries.

The auxiliary engine set-up is with one 8-cylinder Wärtsilä 31DF and one 9-cylinder Wärtsilä 20DF dual-fuel engine. Both act as generating sets for the ship's hotel load, for added propulsion power via the PTI, for low-load operations via PTI, and for charging the batteries. There are also three tunnel thrusters; two in the bow and one located aft.

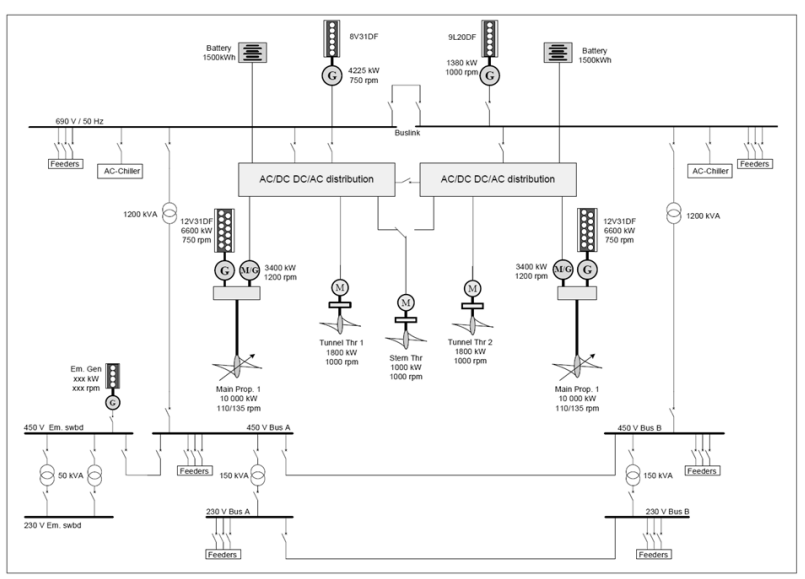

Fig.2 Machinery Single Line Diagram

The configuration illustrated in figure 2 would result in a very flexible and environmentally sustainable vessel, operating on clean LNG with battery assist. During transit the ship's propulsion power would be via the two main engines, with the remaining load being taken from the generating sets and/or batteries. During manoeuvring and at slow speeds, the vessel could operate with up to $3400 \mathrm{~kW}$ on each propeller with electrical power via the frequency drives, from either the generating sets, batteries, or a combination of both. The 2 -speed gearboxes will provide an advantage at slow sailing speeds when operated through the main engines, giving the ability to run the propellers at their most economical speed. The steps used in this example are with propeller speeds of $135 \mathrm{rpm}$ or $110 \mathrm{rpm}$. 


\section{The Wärtsilä 31DF engine}

The use of the Wärtsilä 31DF dual-fuel engine in the above example is deliberate since it represents the very latest in a new generation of medium speed engines where efficiency and overall emissions performance are paramount. If future hybrid vessels are to attain optimal performance, then it naturally follows that both elements - the conventional engine machinery and the energy storage solution - should be optimally efficient.

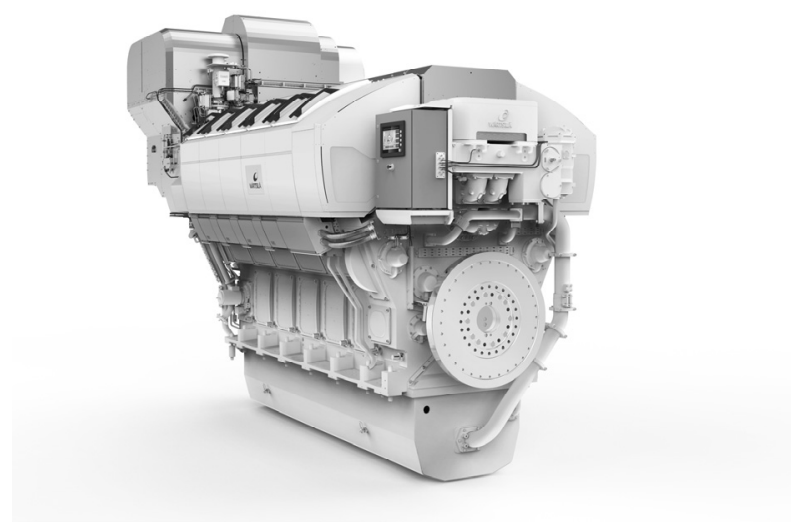

Fig.3 Wärtsilä 31DF engine

Following its introduction in 2015, the Wärtsilä 31 engine was recognized by Guinness World Records as being the world's most efficient four-stroke diesel engine. It is available in diesel, dual-fuel, and pure gas versions, and for our hybrid ferry example, the dual-fuel (DF) version was selected as being the most appropriate. In gas mode it is compliant with the IMO's Tier III regulations without the need for exhaust cleaning systems. Most importantly, the Wärtsilä 31 meets the expectations of ferry operators by trimming fuel costs while simultaneously maintaining the highest standards of environmental performance.

The engine's high efficiency is the result of utilizing the latest technologies. At the same time, the engine parameters have been optimized and designed accordingly, thus providing notable improvements in all areas related to combustion and gas exchange frequency. Friction and heat losses have also been reduced.
The key technologies introduced with this engine include second generation two-stage turbocharging, the common rail fuel injection system, and adjustable inlet and exhaust valve actuation. The outstanding performance across the complete operating range is the result of accurate, as well as an adaptive control system. The advanced Wärtsilä UNIC engine control system utilizes the flexibility of the common rail injection system, as well as the adjustable inlet and exhaust valve timings.

This step change in fuel efficiency is one important ingredient in the recipe for reducing operational costs. In addition, the Wärtsilä 31 is designed for longer intervals between overhauls and a reduced need for maintenance, which also lower the total cost of ownership. Because of its advanced technologies and built-in readiness for possible upgrades, and due to the fact that it can be relied on for many years to come, the Wärtsilä 31 is often referred to as being a future-proof engine.

\section{Batteries}

The use of batteries should always be evaluated on a case-by-case basis. In this example we have assumed a battery capacity of $2 \times 1500 \mathrm{kWh}$. Generally, a battery installation has two main functions, namely Peak Shaving and Battery Operation.

\subsection{Peak Shaving mode}

The batteries will act as a fast response power source and power receiver. This provides the engines with a constant load without picking up the transients from waves and other external forces. The fast response capability enables the variables to be picked up or allows the power to be given, before the engines sense these variations. Figure 4 illustrates a live test set-up with a generating set and batteries. 


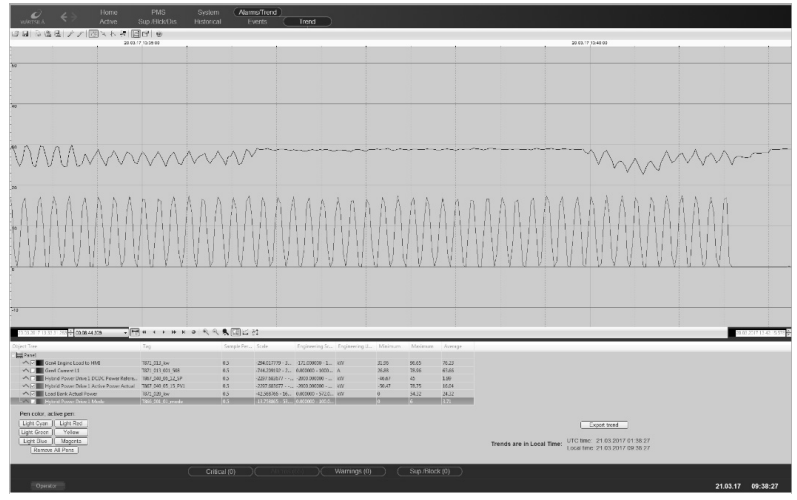

Fig.4 Testing of generating set and battery

The blue curve represents the variation in load, and the black curve is the variation measured on the engines. In the middle of the picture it shows where the batteries are connected and the black curve becomes almost flat. This function will also reduce the thermal load on engine components which can, together with Wärtsilä's Condition Based Monitoring (CBM), further extend overhaul intervals and has been shown also to significantly reduce fuel consumption. The capacity of the batteries for a pure peak shaving operation will normally be in the range of $2 \times 300-500 \mathrm{kWh}$.

\subsection{Battery Operation}

RoPax ferry operations almost always involve situations where, in order to comply with local and/or international environmental legislation, the vessel should run solely on batteries. This could be when the ship is entering or leaving harbour and/or sailing in slow transit areas where low noise and no emissions are essential. The capacity of the batteries will be dependent upon the power needed and the period of time for which battery operation is required. This is something that has to be calculated for each particular vessel. The capacity of the batteries can, in theory, be unlimited and we are already seeing installations having battery capacities of 4000 to $5000 \mathrm{kWh}$.

As regards the charging, it is beneficial wherever possible to charge the batteries during the loading and unloading of the ship. This requires the availability of a power supply on shore.

\section{The control system}

With hybrid propulsion concepts the control system is crucial to achieving high efficiency and economic fuel consumption. The Integrated Automation System (IAS) provides the platform for all information and operation of the vessel while the Energy Management System (EMS) controls and monitors the different energy systems and delivers essential information to the operator. Also integrated into the EMS is a Battery Management System (BMS) for controlling and optimizing battery utilization.

As part of its hybrid power module for ship propulsion, Wärtsilä has developed a highly sophisticated and fully integrated EMS. This is the overall 'brain' controlling the energy flows between the different power sources. It is also possible to add performance optimization features with respect to weather, trim and route, as well as monitoring the long-term performance of the vessel. Furthermore, it creates an entirely new level of interaction with the ship's onboard systems to provide enhanced operability and greater predictability.

This development has been made possible by Wärtsilä's unique in-house expertise in both engine technology and electrical and automation (E\&A) systems. The company has been able to combine these competences to create a deeper level of product control.

\section{Future development of battery technology}

The development of energy storage technology is largely being driven by major industrial forces, such as the automotive, computer, and renewable power industries. It can be expected that the power / energy density of batteries will increase and that costs will eventually be lowered.

Currently energy storage involves trade-offs. You can have lots of power (watts) or lots of energy (watt-hours), but generally you can't have both. Super capacitors can release a massive amount of power, but only for a few seconds. This is a problem because most modern applications require large 
amounts of both power and energy. Lithium-ion batteries are currently the best solution for high power and energy applications. The trade-off between the two still has to be made when creating a new solution.

\section{The use of LNG fuel}

In the earlier example of a hybrid RoPax ferry, the Wärtsilä 31DF dual-fuel engine running primarily on LNG was used. The adoption of LNG as a marine fuel is a trend that is rapidly gaining momentum and is one that will speed up even more as the bunkering infrastructure becomes developed. Two of the main reasons for this are environmental regulatory compliance and economics in the form of fuel prices.

Wärtsilä has established a leading position in LNG propulsion solutions for shipping through its ahead-of-the-game gas engine development work, and also because it quickly recognised that for LNG fuel to become viable in this industry more than just the right kind of engine is needed. Storage, fuel supply, and control systems are all essential elements in the design of a ship running on gas fuel, which is why the Wärtsilä LNGPac system has proven to be so successful.

This too is an area undergoing constant development and upgrading. For example, the LNGPac uses type $\mathrm{C}$ storage tanks, where the only negative aspect is their space requirement. Wärtsilä has now introduced a new type $\mathrm{C}$ tank design combining the benefits of a pressurized tank with the minimized space requirement typical of membrane tanks. These bilobe and multilobe type $\mathrm{C}$ tanks are not a new concept in the cargo industry, but they have not earlier been used for LNG fueled ships.

Alongside these innovations in tank design, Wärtsilä has introduced a number of other innovations that make the use of LNG fuel even more viable. The aim is to reduce exhaust emissions even further, and to minimize energy wastage. One of these patented solutions is the cold recovery system, which uses part of the cold energy from the
LNG for the onboard air conditioning system. In practice this splits the evaporation process of the LNG into two stages; the first working at a low temperature and exchanging cooling power with the ship's HVAC system, while the second stage operates at a higher temperature and recovers part of the otherwise wasted heat from the engines.

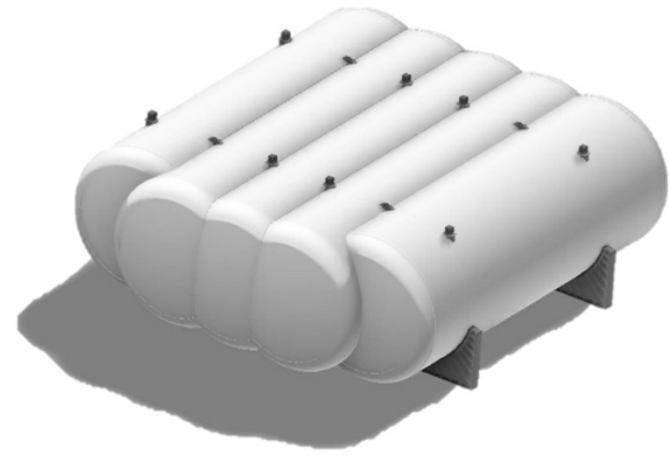

Fig.5 Multilobe type C storage tank

\section{Future-proof ferries}

The design of newbuild RoPax and RoRo ferries is taking on new dimensions necessary to overcome the current industry challenges. The need for greater efficiency, lower operating costs, and reduced total ownership costs, together with increased environmental legislation, are driving new technologies and new ways of thinking about how ferries should function. Hybrid propulsion is an important part of this development. Just as the automotive industry has moved hybrid cars from being merely a hypothetical concept into everyday production models, so too will the shipping industry design and produce modern, efficient, hybrid powered vessels. After all, a newbuild vessel typically has a working life of 20 to 30 years, so it has to be built with a 'future-proof' design with technologies capable of handling the challenges, not only of today, but of tomorrow as well. 


\section{References}

[1] "Wärtsilä Power Electronic Systems Business white paper" (2014)

[2] "Hybrid technology for new emerging markets inductive charging", Ingve Sorfonn, twentyfour7, (2016)

[3] "The new Wärtsilä 31 engine”, Ulf Åstrand, twentyfour7, (2015)

[4] "The new Wärtsilä LNGPac" ${ }^{\mathrm{TM}}$ - a step towards greener shipping", Viktor Bergman and Mathias Jansson, twentyfour7, (2015)

\section{Authors}

- Tillung, Harald

- Business Development Manager

- Concept Developments

•Wärtsilä Marine Solutions

-Zoglia, Piero

- Team Leader,

Sales Engineering

- Fuel Gas Handling

•Wärtsilä Marine Solutions
- Höglund, Nico
- Technical Sales Manager
-Technical Sales,
Engines Business Line
•Wärtsilä Marine Solutions 